\title{
SITE SELECTION AND GROWTH OF THE LARVAE OF EYLAIS DISCRETA KOENIKE, 1897 (ACARI, HYDRACHNELLAE)
}

\author{
by \\ C. DAVIDS, G. J. NIELSEN \& P. GEHRING \\ Zoological Laboratory, University of Amsterdam, The Netherlands
}

\begin{abstract}
The distribution of the larvae of Eylais discreta on the abdominal tergites of the host species Sigara striata, $S$. falleni and Cymatia coleoptrata is examined.

On $S$. striata and $S$. falleni the segments 3 and 4 , on $C$. coleoptrata the segments 2 and 3 are successively preferred. There is but little influence of multiple infestations on this distribution.

The growth rate on the various tergites of $S$. striata is similar, while on $C$. coleoptrata a possible difference could not be proved statistically. The larvae of $E$. discreta generally hibernate on the host; during this phase there is little growth; not until March-April they start growing faster. The larvae on C. coleoptrata are retarded in growth compared to those on $S$. striata.

The larvae on $S$. falleni do not show any increase in size; this water bug species is immune to infestation by various Hydrachnellae.
\end{abstract}

\section{INTRODUCTION}

The larvae of Eylais discreta Koenike, 1897, are parasitic on various genera of corixids (Hemiptera) (Lanciani, 1969; Nielsen \& Davids, 1975). It is known that the attachment of the larvae of Eylais species takes place on the dorsal side of the abdomen, not on the intersegmental membranes but on the tergites themselves.

Lanciani (1969) noted a preference of the larvae of $E$. discreta for the third abdominal tergite in the corixid genera Hesperocorixa, Callicorixa and Sigara. Nielsen \& Davids (1975) observed that the second and third abdominal tergites are preferred by these larvae in Cymatia coleoptrata (Fabricius, 1777) and Sigara striata (Linnaeus, 1758), respectively. The aim of the present investigation is to study the distribution of the mite larvae on the various abdominal tergites and the possible influence of the selected site on the growth rate of the larvae of $E$. discreta.
Such differences in growth rate are known for Arrenurus papillator (O. F. Müller, 1776). The larvae of this species have a larger size on the subcosta than on the anal veins of the wings of dragonflies (Münchberg, 1963). The same holds true for the larvae of Limnochares aquatica (Linnaeus, 1758) attached on the prothorax of Gerridae, compared with those on the meso- and metathorax (Pahnke, 1974).

When studying these phenomena, one has to study the growth first.

\section{METHODS AND RESULTS}

Host insects were collected by dip net on several dates in winter and spring in the surroundings of the "Naardermeer" (a lake $20 \mathrm{~km}$ S.E. of Amsterdam) ard in ditches in the neighbourhood of Purmerland (15 km N. of Amsterdam). In the laboratory the water bugs were preserved in $70 \%$ alcohol and each specimen was checked on mite larvae. The position and length of the mite larvae were determined.

Three corixid species proved to be infested with $E$. discreta larvae, viz. Sigara striata, $S$. falleni (Fieber, 1848) and Cymatia coleoptrata.

\section{Distribution on the abdominal tergites}

The position of the $E$. discreta larvae on the various abdominal segments of the three host species is summarized in table $\mathrm{I}$.

When the mite loads on the various abdominal segments in the course of the season are compared, it appears that on the whole there are no changes in distribution during hibernation and during the growth period of the larvae.

In Sigara striata $14 \%$ of the mite loads were multiple. When we found larvae on tergite 1 and 
Table I. Number of Eylais discreta larvae found on the different abdominal segments of three host species. The total number of corixids examined is indicated as well.

\begin{tabular}{lrrrrrrrrrrr}
\hline Segment no. & 1 & 2 & 3 & 4 & 5 & 6 & 7 & 8 & $\begin{array}{l}\text { number of } \\
\text { hosts }\end{array}$ & $\begin{array}{l}\text { number of } \\
\text { parasitized hosts }\end{array}$ \\
\hline Sigara striata & 3 & 45 & 172 & 108 & 14 & - & - & 1 & 4625 & 240 \\
Sigara falleni & - & 15 & 52 & 24 & - & - & - & - & 710 & 44 & 219 \\
Cymatia coleoptrata & 13 & 140 & 81 & 14 & 1 & - & - & - & 5228 & \\
\hline
\end{tabular}

5 , mostly the host was heavily parasitized. In Cymatia coleoptrata $9 \%$ of the mite loads were multiple and when we found larvae on segment 1 and 4, again mostly the host insect was multiple infested. In $S$. falleni $5 \%$ of the mite loads were multiple.

\section{Growth rate on the hosts}

Eylais larvae grow as well in width as in length, and in the parasitic phase they are about circular.
In comparing width and length measurements, it became clear to us that length could be used as a measure of growth.

The samples were collected in the surroundings of the "Naardermeer" during winter and spring of the years 1972-1973, till the beginning of May when $E$. discreta nymphs leave the host. The data are given in fig. 1 . This figure represents the mean lengths of $E$. discreta larvae taken from all abdominal tergites on the various sampling dates. In autumn there is but little growth (just hatched

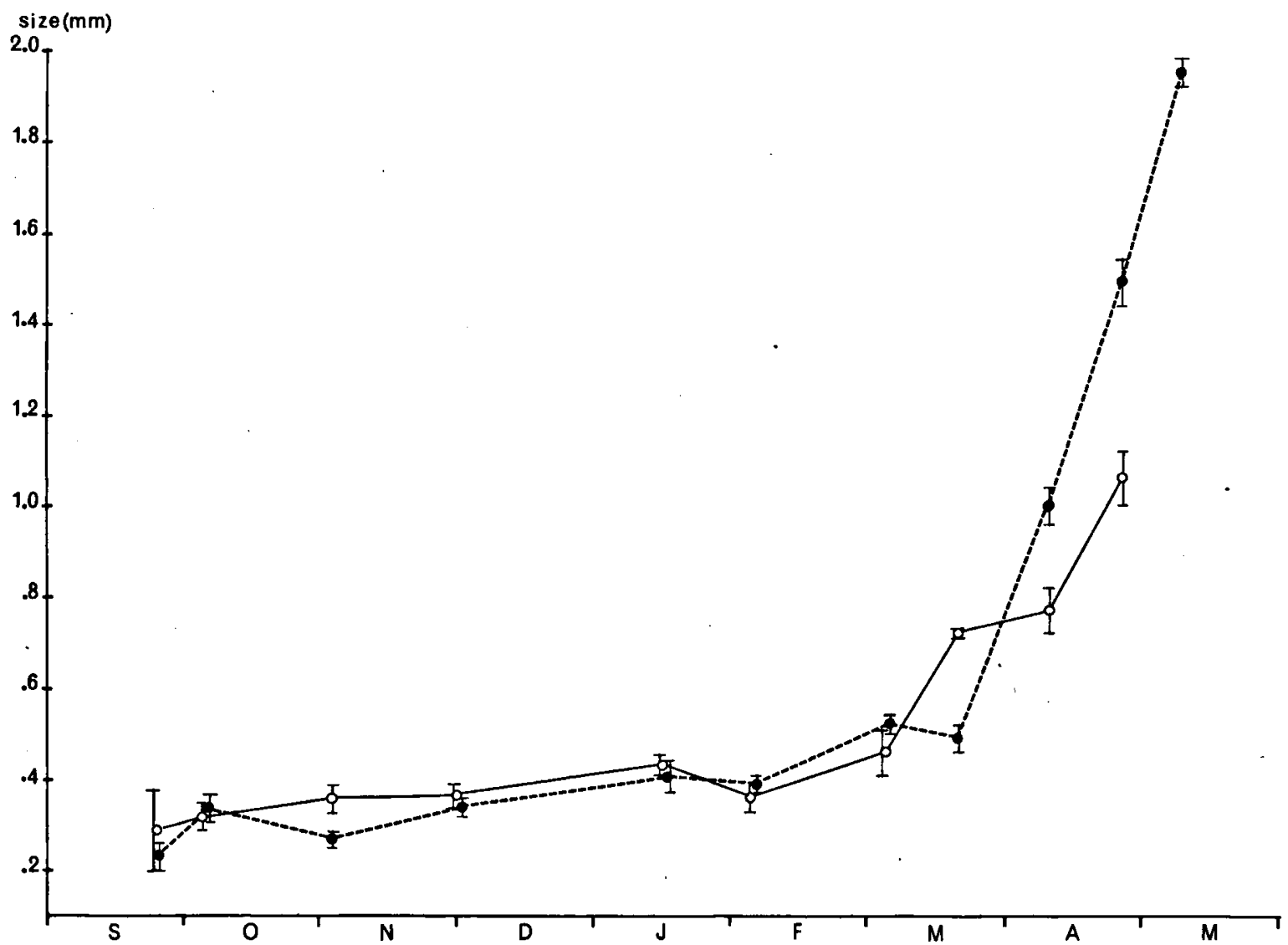

Fig. 1. Mean length of $E$. discreta larvae parasitizing on $S$. striata (O-.-O) and on $C$. coleoptrata (0-0) during winter and spring. Bars represent the standard error.

Number of mite specimens examined on the various sampling dates (26.IX.1972, 6.X.1972, 3.XI.1972, 1.XII.1972, 16.I.1973, 6.II.1973, 5.III.1973, 20.1II.1973, 10.IV.1973, 26.IV.1973 and 9.V.1973): on S. striata 3, 18, 46, 25, 5, 14, 20, 18, 33, 21 and 4, respectively; on C. coleoptrata $3,14,7,10,12,6,2,3,16$ and 18 , respectively. 
larvae measure $200 \mu \mathrm{m}$ in length) and the larvae scarcely increase in size during winter and early spring. As fig. 1 shows, the length of hibernating larvae is about $350 \mu \mathrm{m}$. We also have some data of the winter 1970-1971 and here the length is about $500 \mu \mathrm{m}$. Possibly, water temperatures in autumn are responsible for these differences. In March the growth rate increases rapidly and at the end of April the larvae may have reached lengths up to $2000 \mu \mathrm{m}$.

There is, however, a distinct difference in the growth of $E$. discreta on Sigara striata and on Cymatia coleoptrata. In winter and early spring the growth of $E$. discreta on the two host species is about similar, but in April there is a clear difference. $E$. discreta larvae from the smaller of the two hosts are retarded in growth rate $/ C$. coleoptrata and $S$. striata have a volume of about 4 and $14 \mathrm{~mm}^{3}$, respectively).

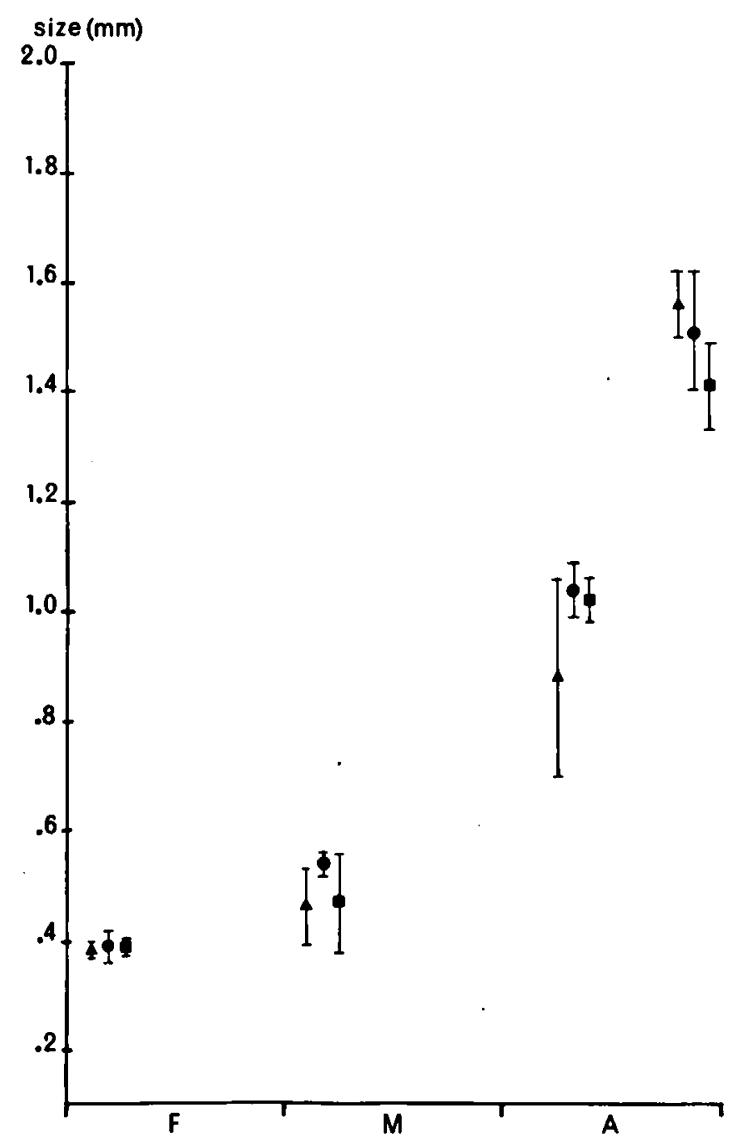

S. falleni was regularly collected together with $S$. striata and $C$. coleoptrata. $E$. discreta larvae choose the same segments in $S$. falleni as in $S$. striata. However, the larvae do not grow on $S$. falleni. This water bug is "immune" to this parasite. In spring fewer mites on $S$. falleni were found than in autumn. Probably the mite larvae die, shrivel and fall from their hosts. On this host species only mite larvae of a length of $200 \mu \mathrm{m}$ are found.

\section{Growth rate on the different abdominal tergites}

Now it becomes clear that possible differences in growth rate on the various tergites have to be examined in a period of real growth, i.e. in April. We have a sufficient number of data on the larvae from abdominal tergites 2, 3 and 4 of Sigara striata. Thus their mean lengths on different dates in spring can well be compared. The results are given in fig. 2 (data of 1973). There is no evidence for differences in growth on these tergites.

The numbers of infested specimens of Cymatia coleoptrata in April are too small to permit conclusions.

\section{DISCUSSION}

The distribution of the $E$. discreta larvae on the abdominal tergites of Sigara striata found by us, agrees with the remarks of Lanciani (1969). We are sure that the tergites 1 and 5 in $S$. striata and 1 and 4 in $C$. coleoptrata are occupied by larvae more frequently in multiple than in single infestations, though not exclusively as Lanciani says. The infection percentage of the bugs in our material was considerably lower than in Lanciani's and the same holds true for the rate of multiple infestations.

In autumn and winter, when there is only a slight growth, the distribution on the tergites is similar to that in April, hence there is no loss from special tergites. To all appearance the larvae complete their development on a once chosen tergite. It remains questionable whether

Fig. 2. Mean length of $E$. discreta larvae on the abdominal tergites $2(A), 3(O)$ and $4(\square)$ of $S$. striata in spring. Bars represent the standard error.

Number of mite specimens examined on the four sampling dates (6.1I.1973, 5.III.1973, 10.IV.1973 and 26.IV.1973): on 2nd tergite $2,3,3$ and 6 , respectively; on 3rd tergite 9, 14, 18 and 8, respectively; on 4th tergite 3, 3, 9 and 7, respectively. 
the corixids are capable of brushing off the larvae.

Not only the larvae of $E$. discreta have a preference for the first abdominal tergites, but also other Eylais species show a comparable preference. Larvae of $E$. setosa Koenike, 1897, are found on the abdominal tergites 1, 2 and 3 of the water beetles Hygrotus inaequalis (Fabricius, 1777) and $H$. versicolor (Schaller, 1783). The same is true for $E$. extendens (O. F. Müller, 1776) larvae on the water beetle Haliplus ruficollis (De Geer, 1774).

By way of exception, we found larvae of $E$. discreta on the underside of a hemi-elytrum, on the head and under the pronotum. Sometimes there is a slight increase in size on these places, but we do not suppose that the larvae will complete their cycle on these attachment sites. Rather often during winter and spring we found larvae between head and pronotum, mostly not attached but free moving. These findings correspond with those of Böttger (1962). According to this author $E$. discreta larvae stay $2-4$ days after infection between head and pronotum, before they crawl to the abdominal tergites in order to attach there. Possibly this will last longer in winter, but it is hard to imagine that it will last for months. This is again an indication (see also Nielsen \& Davids, 1975) that eggs may hatch during winter and spring. From these data it appears too that the larvae move about on their hosts, and thus really can make their choice for the site of attachment.

$E$. discreta larvae have only little growth in winter and early spring, however, in April the growth rate is considerable. A similar growth pattern can be seen in other Hydrachnellae parasitizing corixids, e.g. Hydrachna conjecta
Koenike, 1895, and $H$. cruenta O. F. Müller, 1776 (Davids \& Schoots, 1975). It is striking that in autumn growth must be strongly retarded. Based on temperature only, growth should be as rapid in autumn as in spring. Therefore this retardation should be considered as a diapause. Generally, day length and temperature are the principal inducing factors. It is also possible that development of gonads of the host insects plays a part in this phenomenon. There is some evidence that $E$. discreta larvae in multiple infestations are on an average somewhat smaller than larvae in single infestations, but this could not be demonstrated quantitatively. On the other hand, the distinct difference in growth of $E$. discreta larvae on Sigara striata and on Cymatia coleoptrata is quantitatively proved. The reason why the parasites on $C$. coleoptrata remain smaller can be a matter of food supply.

No differences in growth could be demonstrated on the various abdominal tergites. Although quantitative evidence is lacking, we have the impression that $E$. discreta larvae on the second abdominal tergite of $C$. coleoptrata have a more rapid growth than the larvae on the other abdominal tergites in this host.

It is striking that Sigara falleni is "immune" to $E$. discreta. The same has been found by Davids (1973) for Hydrachna conjecta.

We found the same phenomenon in $H$. cruenta, but it is even more striking that the nymphs of $S$. falleni are not "immune". Larvae of $H$. cruenta attach to the legs of corixids and they parasitize nymphs as well as imagines, in contrast to the other species mentioned. On the nymphs they increase in size but on the imagines they shrivel. Apparently, this "immunity" is built up in the beginning of the adult phase.

\section{LITERATURE}

BötTGER, K., 1962. Zur Biologie und Ethologie der einheimischen Wassermilben Arrenurus (Megaluracarus) globator (Müll.) 1776, Piona nodata nodata (Müll.) 1776 und Eylais infundibulifera meridionalis (Thon) 1899 (Hydrachnellae, Acari). Zool. Jb. (Syst.), 89: 501-584.

Davids, C., 1973. The water mite Hydrachna conjecta Koenike, 1895 (Acari, Hydrachnellae), bionomics and relation to species of Corixidae (Hemiptera). Neth. J. Zool., 23 (4): $363-429$.

DAvids, C. \& C. J. Schoots, 1975. The influence of the water mite species Hydrachna conjecta and $\mathrm{H}$. cruenta (Acari, Hydrachnellae) on the egg production of the Corixidae Si- gara striata and Cymatia coleoptrata (Hemiptera). Verh. int. Verein. theor. angew. Limnol., 19: 3079-3082.

Lanciani, C. A., 1969. Three species of Eylais (Acari: Eylaidae) parasitic on aquatic Hemiptera. Trans. Am. Microsc. Soc., 88: 356-365.

MüNCHBERG, P., 1963. Nochmals zur Biologie und Ethologie der Wassermilbe Arrenurus (A.) papillator (O. F. Müll.), zugleich kritische Bemerkungen zu einigen durch den $\mathrm{Pa}$ rasitismus der Larven der Arrenuri aufgegebenen Problemen (Acari, Hydrachnellae). Gewäss. Abwäss., 32: 44-78.

Nielsen, G. J. \& C. Davids, 1975. Contributions to the 
knowledge of the morphology and biology of the larvae of four European Eylais species (Acari, Hydrachnellae). Acarologia, 17 (3): 519-528.
PahnKe, J., 1974. Anatomisch-biologische Studien an Limnochares aquatica L. (Hydrachnellac, Acari): 1-90, Abb. 1-55 (Thesis, Christian-Albrechts-Universität, Kiel).

Received: I June 1976 